\title{
Empirical Investigation on the Effects of Inter-Firm Technology Transfer Characteristics on Degree of Inter-Firm Technology Transfer: A Holistic Model
}

\author{
Sazali Abdul Wahab \\ National Defense University of Malaysia, Kuala Lumpur 57000, Malaysia \\ Tel: 60-3-9051-3060Ｅ-mail: zali@upnm.edu.my \\ Raduan Che Rose \\ National Defense University of Malaysia, Kuala Lumpur 57000, Malaysia \\ E-mail: raduan@upnm.edu.my \\ Suzana Idayu Wati Osman \\ Felda Global Ventures Holdings, Kuala Lumpur 54000, Malaysia \\ E-mail: suzana.iwo@gmail.com
}

Received: October 23, 2010

Accepted: June 7, 2011 Published: January 1, 2012

doi:10.5539/ass.v8n1p89

URL: http://dx.doi.org/10.5539/ass.v8n1p89

\begin{abstract}
The current issue on inter-firm technology transfer (TT) is centered on the efficiency and effectiveness of the transfer process by the multinationals (MNCs) where the success is strongly associated with degree of technology transferred to local partners. Based on the underlying knowledge-based view (KBV) and organizational learning $(\mathrm{OL})$ perspectives, the main objective of this paper is to empirically examine the effects of four critical technology transfer characteristics: knowledge, technology recipient, technology supplier, and relationship characteristics on two distinct dimensions of degree of technology transfer: degree of tacit and explicit knowledge. Using the quantitative analytical approach, the theoretical model and hypotheses in this study were tested based on empirical data gathered from 128 joint venture companies registered with the Registrar of Companies of Malaysia (ROC). Data obtained from the survey questionnaires were analyzed using the correlation coefficients and multiple linear regression analyses. The results revealed that relationship characteristics have the strongest significant effects on both degrees of tacit and explicit knowledge followed by technology supplier and recipient characteristics. Contrary to the study's prediction, but still consistent with the recent development in literature, knowledge characteristics have only significantly affected degree of explicit knowledge not degree of tacit knowledge. The study has bridged the literature gaps by providing empirical evidence on the effects of four critical technology transfer characteristics: knowledge, technology recipient, technology supplier, and relationship characteristics on two distinct dimensions of degree of inter-firm technology transfer: degree of tacit and explicit knowledge in IJVs in a single model.
\end{abstract}

Keywords: Inter-firm technology transfer, International joint ventures, Degree of technology transfer, Malaysia

\section{Introduction}

The multinational corporations (MNCs) have been regarded as the most efficient vehicle for transferring technology and knowledge across borders through strategic alliances and IJVs (Tihanyi and Roath, 2002; Kagut and Zander, 1993). Therefore, organizations in the developing countries are attempting to collaborate, learn and internalize their foreign partner's technological knowledge by forming strategic alliances and international joint ventures (IJVs) with foreign multinational corporations (MNCs) as an efficient mean to increase their competitiveness, technological capabilities, and potential for local innovation. Nevertheless, the inter-firm technology transfers (TT) in international joint ventures (IJVs) have often involved tradeoffs between the 
technology suppliers' willingness to transfer their considerable amount of technologies; which include tacit and explicit knowledge, degree of protection of the proprietary technology (knowledge and competencies) as the source of the supplier's competitive advantage (Inkpen, 2000), degree of transparency (Hamel, 1991), and motivation to transfer (Szulanski, 1996). Transferring technologies within IJVs have also been subjected to various facilitators, actors and complicated relationship between partners (Szulanski, 1996); which eventually have direct impact on the degree or amount of technology transferred in JVs. The current issue on inter-firm technology transfer (TT) in the developing countries is centered on the efficiency and effectiveness of the transfer process by the multinationals (MNCs) (Pak and Park, 2004; Yin and Bao, 2006). Studies from knowledge-based view (KBV) perspective have acknowledged that MNCs tend to be more protective of their advance technology, knowledge and competencies embodied in products, processes and management because these strategic valuable resources and competencies are their main sources of competitive advantage (Porter, 1985; Barney, 1991; Peteraf, 1993; Wernerfelt, 1984; Pralahad and Hamel). On the other hand, organizational learning (OL) perspective studies have suggested that technology and knowledge tend to be protected by the supplier when the recipients are opportunistic in the collaborative relationship (Inkpen, 1998a; Inkpen and Dinur, 1998; Child and Faulkner, 1998).

Since many studies on inter-firm TT are theoretical (Hamel, 1991; Inkpen, 1998a; Inkpen and Dinur, 1998) and have exclusively focused on a single or few dimensions of TT determinants (Pak and Park, 2004; Yin and Bao, 2006; Hau and Evangelista, 2007) there is a need for more hypothesis development and testing (Huber, 1991; Fiol, 1994). Based on a literature review, studies have shown that possibly there are no empirical studies on inter-firm TT and KT that have simultaneously examined the four TT characteristics: knowledge (KCHAR), technology recipient (TRCHAR), technology supplier (TSCHAR), and relationship (RCHAR) characteristics in a single model. Thus, in order to assess the relative influence of each characteristic on TTDEG, the four critical technology transfer characteristics (TTCHARS) have to be examined simultaneously in a single holistic model (Szulanski, 1996). In the context of inter-firm TT and knowledge transfer (KT), there are inadequate studies which examine all the four TT characteristics in a single model. For example, in the context of Korean's IJVs, Pak and Park (2004) examined two determinants of knowledge transfer: 1) relation-specific variables (equity ownership, conflict, and experience) and 2) knowledge-specific determinants (tacitness and absorptive capacity). Another study by Yin and Boa (2006) examined both supplier individual level and recipient's factors that affect tacit knowledge acquisition in China's JVs. In the context of marketing knowledge acquisition, Hau and Evangelista (2007) examined the effect of knowledge seekers, knowledge holders, and contextual factors on explicit and tacit knowledge acquisition through IJVs in Vietnam. Recent studies have also highlighted that empirical examination of the determinants of cross-border knowledge transfer from MNCs to local firms has been a phenomenon which has not been extensively researched (Pak and Park, 2004; Yin and Bao, 2006). Lai and Narayanan (1996) have stressed the need to systematically investigate the level of technology that is being transferred by MNCs to local industries. This study fills in the literature gaps by empirically examining the effects of all four critical inter-firm technology transfer characteristics (KCHAR, TRCHAR, TSCHAR, and RCHAR) on two dimensions of degree of technology transfer: degree of tacit (TCTDEG) and explicit (EXPDEG) knowledge in a single holistic model using the underlying integrated KBV and OL perspectives. Figure 1 depicts the relationships between the variables in the study's conceptual model.

The present study focuses on the complex process of inter-firm technology transfer: where technology and knowledge are transferred across organizational boundary between unaffiliated partners from different economic and cultural backgrounds. Both TT and KT process in strategic alliances, particularly IJVs, provides the most adequate vehicle for internalizing the partners' competency (Simonin, 1999a; Inkpen, 2000; Inkpen and Dinur, 1998). In the context of this study, the underlying KBV and OL perspectives have indeed contributed valuable understanding and arguments on TT and KT processes in strategic alliance (Simonin, 1999a; Minbaeva, 2007). A review of the literature of both theoretical and empirical studies reveals that the success or failure of inter-firm TT and KT are influenced by various factors which can be broadly categorized as knowledge (KCHAR), technology recipient (TRCHAR), technology supplier (TSCHAR), and relationship (RCHAR) characteristics.

\section{Theory and Hypotheses}

\subsection{Knowledge Characteristics and Degree of Technology Transfer}

Tacit knowledge, which is context-specific, embedded in non-standardized and tailored process, is difficult to acquire and exploit (Polanyi, 1967). Hence, tacit knowledge which is highly personal, deeply rooted in action, commitment, and involvement within a specific context, is hard to be formalized, communicated and shared (Nonaka, 1994). Tacit knowledge is subject to time-compression diseconomies; which means to accelerate tacit knowledge learning is very difficult or perhaps not even possible no matter how much efforts or resources are 
invested to acquire them (Dierickx and Cool, 1989). In the context of OL perspective, tacit knowledge, which is hard to formalize and not easily visible, is difficult to be communicated and shared with the other partners as it involves intangible factors that is embedded in the personal beliefs, experiences, and values of an organization (Inkpen, 1998a, Inkpen and Dinur, 1998).

Past studies have also affirmed the significant effect of knowledge complexity (COMPLX) on knowledge transfer (Simonin, 1999a; 1999b). COMPLX, as a result of the interdependent skills and assets, arises from large numbers of technologies, organization routines, individual and team-based experience (Reed and DeFillippi, 1990). COMPLX of human and technological systems produce a higher level of ambiguity that restrains imitation and impedes transferability. COMPLX as the number of interdependent technologies, routines, individuals and resources is linked to a particular knowledge or assets (Simonin, 1999a). As COMPLX increases, knowledge or technology becomes difficult to transfer or imitate (Kogut and Zander, 1993).

Specificity (SPEC), as the third knowledge characteristic, refers to assets specificity that includes site, physical, dedicated and human assets which are durable investments undertaken in support of particular transaction (Williamson, 1985). Assets specificity as durable investments in specialized equipment, facilities and skilled human resources is not only acting as a source of ambiguity and barrier to imitation but also as a barrier to knowledge transferability (Simonin, 1999a; 1999b). From KBV perspective, a firm creates sustainable competitive advantage by developing valuable assets and competencies which are firm-specific, produce complex social relationships, embedded in the firm's history and culture thus generating organizational tacit knowledge (Lado and Wilson, 1994). As the firm's source of competitive advantage, knowledge or technology which is firm-specific is difficult to transfer (Kogut and Zander, 1993).

H1: Knowledge characteristics, which consist of tacitness, complexity and specificity, are negatively related to degree of technology transfer in IJVs.

\subsection{Technology Recipient Characteristics and Degree of Technology Transfer}

Absorptive capacity (ACAP) is the firm's ability to recognize, assimilate, and apply to commercial ends the value of new external information (Cohen and Lavinthal, 1990). Prior related knowledge, as the important element of ACAP, is critical for organizations to assimilate and exploit new knowledge. By possessing sufficient prior related knowledge, organizations are able to have an adequate ability to absorb new external knowledge (Cohen and Lavinthal, 1990). OL literature suggests that another critical element of ACAP is the recipient's firm intensity of efforts. Intensity of effort is reflected on the amount of energy expended by organizational members to solve problems through organization members directing their considerable time and effort in learning how to solve problems before attempting to solve complex problems (Kim, 1998).

Another important dimension of TRCHAR is recipient collaborative (RCOL). RCOL is closely related to the recipient's learning intent (competitive vs. collaborative intent). The technology recipient firm's willingness to establish a mutually beneficial and collaborative relationship requires the recipient firm's honest intention to create common benefits for both JV partners (Yin and Bao, 2006). Studies on inter OL have suggested that cooperative/collective learning encourages the alliance partners to work together by sharing their knowledge, benefit each other's complementarities and provide mutual opportunities to extract potential synergies between their respective competencies (Doz, 1996; Geringer, 1991). Collaborative learning creates an access to the partner's knowledge and skills such as product and process technology, organizational skills, and knowledge about new environments (Inkpen, 1995a). In the collaborative learning environment; where the recipient's learning intent is crucial, the transferring partner tends to be more open or transparent in terms of sharing and transferring knowledge to the acquiring firm as it involves mutual exchange of valuable knowledge (Inkpen, 2000). RCOL, which is reflected on the partner's learning intent, determines the degree of openness or transparency in knowledge sharing and knowledge transfer (Inkpen, 2000).

H2: Technology recipient characteristics, which consist of absorptive capacity and recipient collaborativeness, are positively related to degree of technology transfer in IJVS.

\subsection{Technology Supplier Characteristics and Degree of Technology Transfer}

Partners in the collaborative relationship such as JVs are expected to mutually exchange their valuable assets, resources, information, knowledge and technology between them in order to achieve mutual benefits (Inkpen, 2000; Khanna et al., 1998; Child and Faulkner, 1998). KBV perspective suggests that since the firm's competencies are the sources of technology-supplier's sustainable competitive advantage therefore for fear of losing ownership of their valuable assets they tend to protect their competencies from the opportunist recipient partner (Barney, 1991; Cohen and Lavinthal, 1990; Hamel, 1991). Partner protectiveness (PPROTEC) is closely 
related to partner's transparency or openness (Hamel, 1991). Relationship openness has been described as 'the willingness and ability of JVs' partners to share information and communicate openly' (Inkpen, 2000). Most of the researchers are in consensus that the extent of willingness of the JV's partners to share and transfer knowledge is associated with partner protectiveness and transparency (Hamel, 1991; Inkpen, 2000). Studies have suggested that if a situation of high competitive overlap exists, an alliance partner may be very reluctant to share knowledge due to risk of knowledge 'spillovers' to the other partner (Inkpen, 1998a; Inkpen, 2000; Yan and Luo, 2001).

As for the technology-supplier's transfer capacity (TRANSCAP), many studies have suggested that while firms differ in their ability in creating knowledge, they also differ in their ability to transfer knowledge within or outside of the organization boundary (Kogut and Zander, 1992, 1993; Szulanski, 1996). The efficiency in transmitting technology or knowledge by the supplier is important in both intra and inter-firm knowledge transfer as it affects the TT outcomes (Martin and Solomon, 2003). In the context of strategic alliance, the supplier firms' ability to transfer knowledge facilitates the organizational learning process and justifies their commitments in the collaborative relationship; where all partners are expected to mutually contribute their knowledge, technologies, skills and competencies to the JVs to gain mutual benefits (Inkpen, 1998a, Inkpen 2000; Khanna et al., 1998; Child and Faulkner, 1998).

H3: Technology supplier characteristics, which consist of low partner protectiveness and transfer capacity, are positively related to degree of technology transfer in IJVs.

\subsection{Relationship Characteristics and Degree of Technology Transfer}

OL literature suggests that acquiring and transferring technology require frequent and effective interactions between the supplier and recipient as knowledge is firm-specific, embedded in firm organizational context, personal quality in nature and idiosyncrasy (Nonaka, 1994; Kogut and Zander, 1992, 1993; Bresman et al., 1999). RELQLTY promotes intimacy of relationship between the source and recipient unit (Szulanski, 1996), informality, openness and density of communication (Gupta and Govindarajan, 2000), and increases openness of communication, spontaneous and open exchange of information between interacting parties (Gupta, 1987). In the context of strategic alliance, RELQLTY promotes greater opportunities to learn, share and access alliance partners' strategic knowledge and competencies. It also creates higher relationship openness which could directly affect the willingness of alliance partner to share information and communicate openly (Inkpen, 1998a, 2000).

With respect to mutual trust (MT) between partners, previous studies have suggested that MT creates opportunities for a mutual inter-organizational learning when partners become more open and committed in sharing their knowledge and competencies, less protective of their knowledge, and develop free exchange of information between partners (Inkpen, 2000). When the level of transparency or openness between the alliance partners is high, the propensity for inter-partner learning is also high as knowledge is more accessible due to free exchange of information (Hamel, 1991; Doz and Hamel, 1998; Inkpen, 2000). MT encourages partners to be more open and transparent in exchanging, sharing, and transferring knowledge and technology between them due to non-existence of opportunistic behaviors (Kale et al., 2000; Gulati, 1995; Uzzi, 1997; Child and Faulkner, 1998; Steensma and Lyles, 2000; Lane et al., 2001). MT is found to have reduced search cost, increased benefits and alliance's performance (Gulati, 1995), increased alliance's cooperation, improved flexibility, reduced the coordinating activities cost, and increased knowledge transfer and learning (Smith et al., 1995).

H4: Relationship characteristics, which consist of relationship quality and mutual trust, are positively related to degree of technology transfer in IJVs.

\section{Methods}

\subsection{Sample}

The sample frame was taken from the IJV companies registered with the Registrar of Companies (ROC). As at $1^{\text {st }}$ January 2008, the number of IJVs operating in Malaysia was 1038. Out of this, 850 IJVs were considered as active IJVs and $103 \mathrm{IJVs}$ were either dormant or had ceased operation. Since the focus of this study is on inter-firm TT from foreign MNCs to local companies, $85 \mathrm{IJVs}$ were further eliminated from the population frame because only IJVs that have operated more than 2 years and have at least twenty percent (20\%) of foreign equity are eligible to participate in the survey. Therefore, based on the list provided by ROC, which is considered as the most official and original source of information on foreign investment in Malaysia, it was decided that all IJVs (850) be included in the survey. Data collection was conducted in the period from July 2008 to December 2008 using a self-administered questionnaire. The questionnaires were mailed to 850 active JV companies as listed 
with ROC using a cover letter. After one month from the posting date the response was found not encouraging. By mid July 2008 there were only 70 responses received from the respondents. Thus, in order to increase the response rate the researcher followed-up through numerous phone calls, e-mails, reminders via letters and personal visits to seek the respondents' cooperation in the survey. After intensive efforts were made, by mid November 2008 a total of 145 responses $(17.05 \%)$ were received. Based on literature review, the response rates for mailed questionnaires are usually not encouraging and low (Newman, 2003; Sakaran, 2003). In the Malaysian context, however, a response rate of $15 \%$ to $25 \%$ is still being considered appropriate and acceptable (Mohammed, 1998; Rozhan, Rohayu and Rasidah, 2001). From 145 responses only 128 questionnaires were usable and 17 questionnaires were returned blank, returned incomplete, or replied but unable to participate in the study.

\subsection{Instrument and measurement}

The main research instrument in this study is the questionnaire. Building on the previous KT and TT studies, the questionnaire adopts a multi-item scales which have been modified accordingly to suit the context of the study: inter-firm TT. Except for degree of technology transfer (TTDEG), all the variables are measured using ten-point Likert Scale $(1=$ strongly disagree to $10=$ strongly agree). For TTDEG, this variable is measured using ten-point Likert Scale $(1=$ very low transfer to $10=$ substantial transfer). The ten-point Likert Scale was selected because 1) the wider distribution of scores around the mean provides more discriminating power, 2) it is easy to establish covariance between two variables with greater dispersion around their means, 3) it has been well established in academic and industry research, and 4) from a model development perspective, a ten-point scale is more preferred (Allen and Rao, 2000).

\subsection{Dependent Variable - Degree of Technology Transfer (TTDEG)}

Following Lyles and Salk (1996), Lane et al. (2001), Gupta and Govindarajan (2000), Dhanaraj et al. (2004), Pak and Park (2004), Yin and Boa (2006) and Minbaeva (2007), this study adopts "a multi-dimensional operationalization approach" in measuring this construct. This study operationalizes TTDEG as the transfer of technological knowledge in terms of two dimensions: 1) tacit knowledge (TCTDEG) in terms of new product/service development, managerial systems and practice, process designs and new marketing expertise, and 2) explicit knowledge (EXPDEG) in terms of manufacturing/service techniques/skills, promotion techniques/skills, distribution know-how, and purchasing know-how. The respondents were asked to evaluate TTDEG from MNCs to local firms in terms of tacit and explicit dimensions of technological knowledge. The Cronbach Alphas for TCTDEG and EXPDEG were 0.96 and 0.97 respectively. The results of Cronbach Alpha were quite similar to that of Hau and Evangelista (2007) and Yin and Bao (2006).

\subsection{Independent Variables}

\subsubsection{Knowledge Characteristics (KCHAR)}

This study focuses on three critical attributes of KCHAR: tacitness (TCT), complexity (COMPLX), and specificity (SPEC); which have significantly contributed to knowledge ambiguity (Reed and DeFillippi, 1991; Simonin, 1999a). This study captures the taxonomic dimension of knowledge (tacit vs. explicit dimension) (Winter, 1987) and knowledge ambiguity (Kogut and Zander, 1993; Zander and Kogut; 1995).

\subsubsection{Tacitness (TCT)}

This study measures TCT in terms of its two constructs: codifiability and teachability (Kogut and Zander, 1993; Simonin, 1999a, 1999b, 2004). For codifiability, multi-item scales are designed to capture the extent to which the technology has been articulated in documents. Two (2) items are adopted from Kogut and Zander (1993) and modified accordingly to suit the context of this study which includes statements as to whether 1) the foreign JV partner's manual describing the technology can be written, and 2) large parts of the foreign JV partner's technology are embodied in standard software. Two (2) items are adopted from Simonin (1999a, 1999b, 2004) which include statements whether 1) the foreign JV partner's technology is easily codified, and 2) the foreign JV partner's technology is more explicit than tacit. One (1) item is adopted from Pak and Park (2004) inquiring whether the partner's technology is hard to verbally transfer. For teachability, the scales are designed to capture the ease by which technology can be learned by the local JV partner. Three (3) items are adapted from Kogut and Zander (1993) and modified accordingly to suit the context of the study which include statements whether 1) the local JV firm's personnel can easily learn the technology by communicating with the foreign JV partner's skilled personnel, 2) the local JV local firm's personnel can easily learn the technology by studying a complete set of blueprints, and 3) educating and training the JV local firms' personnel is a quick and easy process. The Cronbach Alpha for TCT was slightly higher (0.86) than Simonin's (1999a) Cronbach Alpha (0.72). 


\subsubsection{Complexity (COMPLX)}

Following Simonin (1999a, 1999b, 2004) and Kogut and Zander (1992, 1993), this study adopts a five (5) items scale in measuring COMPLX which include statements whether the JV partner's technology is the product of many interdependent techniques, routines, individuals, resources, and processes. The Cronbach Alpha for COMPLX was slightly higher (0.84) than Pak and Park's (2004) Cronbach Alpha (0.74).

\subsubsection{Specificity (SPEC)}

To capture SPEC this study adopts a two (2) items scale from Simonin (1999a, 1999b) in terms of whether 1) the foreign JV partner has invested significantly in specialized equipment and facilities in developing their technology, and 2) the foreign JV partner has invested significantly in skilled human resources in developing their technology. Following Pak and Park (2004), this study also adopts one (1) item scale which includes a statement on whether the technology is difficult to access from the other company. For SPEC the Cronbach Alpha was slightly lower (0.72) as compared to Pak and Park's (2004) Cronbach Alpha (0.87).

\subsubsection{Technology Recipient Characteristics (TRCHAR)}

This study concentrates on two distinct elements of TRCHAR: absorptive capacity (ACAP) and recipient collaborativeness (RCOL); which have strong theoretical and empirical supports (Cohen and Levinthal, 1990; Hamel, 1991; Simonin, 1999a). This study captures the technology recipient's capability, willingness to absorb new knowledge and attitude towards learning.

\subsubsection{Absorptive Capacity (ACAP)}

Building on Lane et al. (2001), this study captures ACAP's critical elements of ability to understand, assimilate and apply new external knowledge. In capturing these critical elements, this study adopts a multi-item scale previously used by the researchers (Lyles and Salk, 1996; Simonin, 1999a; Pak and Park, 2004) to measure the constructs using seven (7) items with respect to statements on the academic background, technical capacity, educational programs, financial support for new ideas, overseas training opportunities, and commitment in terms of personnel and resources (physical, financial, and logistic) to JV. Following Cohen and Levinthal (1990) and Lane et al. (2001), this study also includes one (1) item to assess the local firm's ability to understand, assimilate and apply new technology transferred by the foreign parent firm.

The Cronbach Alpha for ACAP was higher (0.94) than Simonin's (2004) Cronbach Alpha (0.81).

\subsubsection{Recipient Collaborativeness (RCOL)}

This study measures RCOL in terms of the local partner firms' learning intent and their collaborative attitudes by using a five (5) items scale in terms of 1) the local partner's learning objective, 2) the local partner's desire, determination and will to learn from foreign partner, 3) the technology-recipient's willingness to allow foreign partner to inspect and monitor the use of knowledge acquired from JV, 4) the local partner's commitment not to compete directly with the foreign partner in the future, and 5) the local partner's commitment in sharing with the foreign partner the benefits of the critical knowledge acquired from the JV (Yin and Bao, 2006; Thuc Anh et al., 2006; Hamel, 1991; Simonin, 2004). The Cronbach Alpha for RCOL was higher (0.92) than Yin and Bao's (2006) Cronbach Alpha (0.71).

\subsubsection{Technology Supplier Characteristics (TSCHAR)}

This study focuses on two important elements of TSCHAR: partner protectiveness and transfer capacity; which represent the sender's attitudes and behaviors to share technology/knowledge (Simonin, 1999b; Hau and Evangelista, 2007; Minbaeva, 2007). This study captures the technology supplier's capability, level of transparency, and willingness to share knowledge.

\subsubsection{Partner Protectiveness (PPROTEC)}

The measure of PPROTEC is adopted from Simonin (1999a, 1999b and 2004). In measuring this construct, this study adopts a two (2) items scale which includes statements whether 1) the foreign JV partner has intentional procedures, routine and policies to restrict the sharing of relevant information concerning its technology know-how, and 2) the foreign JV partner is very protective of its technology know-how (Simonin, 1999a). This study also adopts two (2) newly developed items by Hau and Evangelista (2007) namely 1) the restrictive policy of the foreign partner with respect to knowledge spillovers to the other partner; and 2) the unwillingness of the foreign expatriates to share technological expertise with the local firms' personnel. The Cronbach Alpha for PPROTEC was slightly higher (0.84) than Simonin's (1999a) Cronbach Alpha (0.77). 


\subsubsection{Transfer Capacity (TRANSCAP)}

To operationalize the ability of foreign JV's partner to articulate, communicate and transfer technology to local firms, this study employs a four (4) items scale which consists of two (2) items adopted from Lyles et al. (1999), and two (2) items from Hau and Evangelista (2007). The respondents are asked to indicate whether 1) the foreign JV partner has provided the local partner with materials on procedures and guidelines for technology planning and decision making, 2) the foreign JV partner has offered formal training programs such as seminars and lectures to the local firm's personnel (Lyles et al., 1999), 3) the training programs provided by the foreign JV partner have been very helpful to the local firm's personnel, and 4) there have been many foreign JV partner personnel working in the JV firm (Hau and Evangelista, 2007). The Cronbach Alpha for TRANSCAP was higher (0.92) than Minbaeva's (2007) Cronbach Alpha (0.66).

\subsubsection{Relationship Characteristics (RCHAR)}

This study focuses on two distinct elements of RCHAR: relationship quality and mutual trust; which have been extensively dealt by theoretical studies (Gupta, 1987; Szulanski, 1996; Kale et al., 2000). This study captures the closeness of relationship, ease of communication and intimacy of relationship between the recipient and supplier (Minbaeve, 2007; Szulanski, 1996)

\subsubsection{Relationship Quality (RELQLTY)}

This study operationalizes RELQLTY in terms of relationship informality, openness and communication density; which increases the exchange of information, technology and knowledge between partners (Gupta, 1987; Gupta and Govindarajan, 2000; Lin, 2005). To capture this construct, this study employs a four (4) items scale developed by Lin (2005) in which the items are designed to capture 1) the local JV partner efforts in maintaining frequent interaction with the foreign JV partner, 2) the adequacy of the interaction, 3) the local JV partner effort in maintaining an amiable climate for the interaction, and 4) the local JV partner's effort in ensuring that interaction is on a constructive mode. As RELQLTY (informality, openness and communication density) is explained by the relationship strength, this study adopts a seven (7) items scale adopted from Cavusgil et al. (2003), Chua (2002), and Fryxell et al. (2002). RELQLTY is measured in terms of 1) the desire to maintain a good social relationship by the foreign and local JV partners, 2) the foreign and local JV partners can freely talk to each other about difficulties (in general) they encounter with JV and they know that their concern will be addressed, 3) the foreign and local JV partners are confident in each other's capabilities, 4) the foreign and local JV partners are free to share their ideas, feelings and hope with each other, 5) the foreign and local JV partners are supportive of each other and they respond constructively and caringly to their partner's concern about the JV, 6) the foreign and local JV partners share a sense of togetherness, and 7) the foreign and local JV partners share organizational myths and stories with each other. The Cronbach Alpha for RELQLTY was slightly higher (0.96) than that of (Lin, 2005).

\subsubsection{Mutual Trust (MT)}

This study employs a six (6) items scale developed by Dhanaraj et al. (2004) and five (5) item scales from Kale et al. (2000) to measure MT between JV partners which include statements whether 1) the JV partners can understand each other well and quickly, 2) the JV partners have the feeling of being mislead, 3) the JV partners make damaging demands, 4) the stronger JV partner pursues its interest at all costs, 5) the informal agreement are perceived as significant as formal agreement, and 6) the JV partners take advantage on the weakness of the other party (Dhanaraj et al. , 2004). In addition, five (5) more items are adopted from Kale et al. (2000) with respect to statements whether the JV is characterized by close interaction, mutual respect, mutual trust, personal friendship, and reciprocity between the JV partners at multiple levels. The Cronbach Alpha was lower slightly lower (0.88) than Dhanaraj et al. (2004).

\section{Results}

Table 1 shows the descriptive data of all the variables (Mean values, Standard Deviations, Correlations). The results of regression analysis are presented in Table 2.

From Table 1 above, there are clearly some associations between independent variables. For all the variables, it was found that there was no multicollinearity problem; where the $\mathrm{T}$ values were ranged between $0.635-0.827$ and the VIF values were between 1.211 - 1.575. Relationship characteristics (RCHAR) had the highest correlation with both degrees of tacit knowledge (TCTDEG) and explicit knowledge (EXPDEG) $(p<0.01)$ followed by technology recipient characteristics (TRCHAR) $(p<0.01)$ and technology supplier characteristics (TSCHAR) $(p<0.01)$ suggesting that high degrees of RCHAR, TRCHAR and TSCHAR are associated with high degrees of tacit (TCTDEG) and explicit knowledge (EXPDEG). It is interesting to note that although 
knowledge characteristics (KCHAR) have been extensively dealt with by the literature, however, their correlations with TCTDEG and EXPDEG were not statistically significant $(p>0.05)$ although the negative directions were correctly predicted. On the high correlations between RCHAR and both TCTDEG and EXPDEG, the results are in line with the current proposition by the literature which suggested that the role of KCHAR as the most important knowledge transfer determinant has not only been superseded by TRCHAR and TSCHAR but also by RCHAR (Szulanski and Cappetta, 2003; Hansen and Lovas, 2004).

Using multiple regression analysis, the effects of KCHAR, TRCHAR, TSCHAR and RCHAR on two dimensions of degree of technology transfer (TCTDEG and EXPDEG) were estimated. As shown in Table 2, RCHAR, as one of the critical elements of technology transfer characteristics had a significant positive effect on degree of tacit knowledge (TCTDEG) $(p<0.001)$. The regression results in Model 1 suggest that the greater (closer) the relationship between JV partners the higher the degree of tacit knowledge transfer. As compared to Model 1, although the regression results in Model 2 recorded a similar significant positive effect of RCHAR on EXPDEG $(p<0.001)$, however, its Beta value $(0.489)$ was slightly higher than Model 1 (Beta value $=0.371)$ indicating that by having a close, intimate and cordial relationship between JV partners, more explicit technology are likely to be transferred to the recipient partners than tacit technology. As the critical element of relationship characteristics, RCHAR had a highly significant effect on both degrees of tacit and explicit knowledge ( $p<$ 0.001). From the regression results $H 4$ is supported.

Model 1 further shows that TRCHAR had the second strongest significant positive effect on TCTDEG $(p<0.01$, Beta value $=0.201$ ) suggesting that a greater absorptive capacity; which is supported by the collaborative learning attitude of the technology recipient would likely to increase the supplier partner's willingness (motivation) to transfer a higher degree of tacit knowledge smoothly than explicit knowledge in the collaborative IJV since the technologies that the recipient partner wishes to exploit are closely related to their current knowledge base. Interestingly, although absorptive capacity and recipient collaborativeness were among the critical elements of TRCHAR which have been strongly highlighted by previous literature of their significance, however, their combination have failed to provide significant effect on EXPDEG $(p>0.05)$. In Model 2 TRCHAR had only a very low significant positive effect on EXPDEG $(p<0.10$, Beta value $=0.148)$ suggesting that the presence of sufficient level of absorptive and collaborative learning intent does not necessarily increase degree of explicit knowledge. This is because although explicit knowledge is mostly codified in the form of blueprints, instructions, formulas or standard manuals by the supplier it still implicitly consists of an intrinsic tacit element/value; where to accelerate the transfer of EXPDEG would involve various organizational levels in organizations. Transferring explicit knowledge of a highly specific and complex technology/knowledge requires not only learning by doing by the recipient but also active involvement of the teacher/supplier. Thus, based on the regression results in Model 1 and Model 2, H2 is partially supported.

Consistent with the study's prediction, TSCHAR (low partner protectiveness and transfer capacity) which have strong theoretical foundation showed significant positive effects on both TCTDEG and EXPDEG $(p<0.05$ and $p<0.01$ respectively). As compared to the effect of TSCHAR on EXPDEG $(p<0.01$, Beta value $=0.237)$ in Model 2, TSCHAR recorded slightly less strong effect on TCTDEG in Model $1(p<0.05$, Beta value $=0.164)$ suggesting more dominant role played by TSCHAR in influencing higher degree of explicit knowledge than tacit knowledge in IJVs. Therefore, $H 3$ is supported since more tacit and explicit knowledge will likely be transferred to recipient when 1) a high degree of openness or transparency exist between IJV partners and 2) the supplier partners have the ability to transfer both tacit and explicit technologies effectively to the recipient partners.

The regression results further indicate that as compared to Model 1, KCHAR in Model 2 had a strong significant negative effect on degree of explicit knowledge $(p<0.05$, Beta value $=-0.175)$ suggesting that the higher the level of knowledge tacitness, complexity and specificity of the foreign partners' technology the lesser the degree of explicit knowledge that are transferred to the recipients/local partners in IJVs. The effect of KCHAR on TCTDEG was found insignificant $(p>0.05$, Beta value $=-0.079)$. Surprisingly, although KCHAR have been strongly highlighted by the literature of its significance negative role, it has failed to provide any significant effect on TCTDEG although the direction was correctly predicted. The results also suggest that even though explicit knowledge, which is frequently standardized in the form of standard manuals, procedures, and blueprints, is less 'stickier' than tacit knowledge; however, it still remains difficult to transfer explicit knowledge within IJVs due to its high intrinsic tacit element. Thus, $H 3$ is partially supported.

\section{Discussion and Conclusion}

The results are in line with the proposition made by the literature which suggested that KCHAR, as the most important knowledge transfer determinant, have not only been superseded by TRCHAR and TSCHAR but also 
by RCHAR (Minbaeve, 2007; Szulanski and Cappetta, 2003; Hansen and Lovas, 2004). As compared to Minbaeva's (2007) empirical findings; where RCHAR were ranked as second important determinant of knowledge transfer, the results of the present study offer a different view in terms of the strength of significance level of technology transfer characteristics. The results provide empirical evidence in supporting RCHAR as the most important characteristics of inter-firm technology transfer. The results suggest that the greater (closer) the relationship between IJV partners the higher the degree of TT. Many theoretical studies on strategic alliance have also stressed on the importance of having close relationship between collaborative partners in promoting openness/transparency between partners, and mutual trust (Inkpen, 1998a, 2000, Hamel, 1991). The empirical data provides significant evidence that RCHAR, in terms of frequent and effective interactions, multiple individual exchanges, productive and adequacy of interaction, and intimacy of relationship, are more likely to contribute to an increase of 1) relationship openness/transparency that reduces partner protectiveness, 2) opportunity to learn, share and access to both JV partners strategic knowledge and competencies, 3) resource commitments in JV, and 4) mutual trust between JV partners.

The results further suggest that RCHAR were critical in JVs because only through close interactions can both tacit and explicit technologies be easily accessed, shared, and transferred. The results are consistent with several empirical studies such as Minbaeva (2007), Pak and Park (2004), and Yin and Bao (2006). RCHAR, as the strongest technology transfer characteristics, becomes a major concern among the sample population for their role in facilitating a greater transfer of both tacit and explicit technologies in IJVs. Interestingly, the results extend Pak and Park's (2004) findings by discovering that RCHAR have not only significantly affected degree of tacit knowledge (TCTDEG) in IJVs but also degree of explicit knowledge (EXPDEG). The results also suggest that there is no difference in terms of the level of significance of RCHAR in affecting both TCTDEG and EXPDEG (both at $p<0.001$ ). The plausible explanation on the significant effect is that, although explicit knowledge is well standardized in blueprints, manuals, procedures and instructions as provided by the supplier, the articulation of explicit technology/knowledge in 'the teacher-student context' requires that both JV partners to have frequent interactions at various organizational levels. The quality of relationship and mutual trust act as efficient mechanisms which directly increase openness/transparency between partners resulting in a higher degree of tacit and explicit technology be transferred to the recipient.

The results are in line with the recent propositions in literature; where the information provider attributes have also surpassed the important role of knowledge attributes. The empirical evidence had established that TSCHAR (the information provider) had overridden KCHAR as the most important determinant of knowledge transfer (Minbaeva, 2007; Szulanski and Cappetta, 2003). The presence of a strong impact on TCTDEG and EXPDEG suggests that more tacit and explicit technologies will be transferred to the local recipients when 1) a high degree of openness or transparency exist between IJV partners and 2) the supplier partners have the ability to transfer technology effectively to the local recipients. Consistent with the empirical findings by Minbaeva (2007) and Yin and Bao (2006); where TSCHAR were found to have significantly affected both knowledge transfer and tacit knowledge acquisition, the results further extend the literature by providing empirical evidence on the strong positive effect of TSCHAR on both degrees of tacit and explicit knowledge $(p=0.05$ and $p<0.01$ respectively). The plausible explanation is that the transfer of both tacit and explicit knowledge in IJV frequently requires the supplier partners to become 1) proficient and more articulate in describing the potential uses of the knowledge and conditions as to what the knowledge could achieve (Martin and Solomon, 2003), and 2) more transparent in the transfer process since it involves various organizational levels and actors (Inkpen, 2000). The results also suggest that the transferring partners in IJVs were reasonably satisfied with the recipient's collaborative learning intent; which has directly increased trust between partners thus suggesting that the supplier partners could have been motivated to transfer more tacit and explicit technologies when they become less suspicious of the recipient partners (Inkpen, 2000). The empirical data finds support that 1) the supplier's transparency during the transfer process is a key element in determining the amount of technology transferred in IJVs, and 2) a higher degree of transparency by the supplier partner is motivated by the collaborative attitude and reciprocity on the part of the recipient (Hamel, 1991).

The effects of TRCHAR on both TCTDEG and EXPDEG are quite consistent with the previous findings as reported in the literature; which suggest that the technology recipient characteristics have a significant strong positive effect on degree of technology transfer (Yin and Bao, 2006, Minbaeva 2007; Pak and Park, 2004; Hau and Evangelista, 2007). A higher degree of technology is likely to be transferred to the recipient who possesses high absorptive capability; which is reflected on the recipient's basic/minimal skills, a shared language, positive attitude towards learning, relevant prior experience, up-to-date knowledge on the knowledge domain that the recipient wishes to exploit, and intensity of efforts (Cohan and Lavinthal, 1990; Kim 1998). More importantly, 
as learning new technologies in IJVs demands active involvement by the MNCs' parent company and their involvement at various organizational levels, therefore before technology/knowledge can possibly be transferred, knowledge must be connected through various levels (individual, group and organization) to create potentials in sharing the observations and experiences (Inkpen, 2000; Nonaka, 1994). As the second group of technology transfer characteristic, TRCHAR (which comprised of ACAP and RCOL) have consistently been found to have a strong significant positive effect on TCTDEG than EXPDEG. The results are not consistent with the general empirical findings by literature on the significant effect of TRCHAR on knowledge transfer (Minbaeva, 2007; Yin and Bao, 2006; Pak and Park, 2004; Hau and Evangelista, 2007); where in this study TRCHAR were only found to be highly significant in affecting the transfer of tacit knowledge but not explicit knowledge ( $p$ value $<$ 0.05 and $p<0.10$ respectively). This new insight is interesting as it extends the previous literature's findings in such that all the previous findings have found similar effects of TRCHAR on both tacit and explicit knowledge in JVs (Pak and Park, 2004; Hau and Evangelista, 2007). The plausible explanation to the results is that tacit knowledge which is ambiguous, complex, and highly specific in nature is more difficult to be explicitly articulated, shared, and transferred to the recipient because tacit knowledge is embedded in the context and idiosyncrasy of the supplier organizations. In addition, the empirical data also suggests that the successful transfer of tacit and explicit knowledge to the recipient in IJVs depends on the recipient's collaborative attitudes towards achieving mutual benefits and organizational learning (Inkpen, 2000; Child and Faulkner, 1998). Thus, the recipient's learning intent is critical as a mechanism to encourage the supplier's openness/transparency to share and transfer higher technology. The empirical data supports the proposition that the recipient's collaborative learning intent creates potentials for a higher degree of knowledge sharing, mutual trust, and opportunities to extract higher synergy between JV partners.

The results of the significant effect of KCHAR on EXPDEG were consistent with the findings by Pak and Park (2004); where KCHAR's effect on manufacturing-processing (explicit knowledge) was found more dominant than their effect on new product development (tacit knowledge). The results are quite interesting given that although explicit knowledge is mostly codified in the form of blueprints, instructions, formulas or standard manuals by the supplier, transferring explicit knowledge would be a challenge if they are firm-specific and consist of high intrinsic tacit elements. Explicit knowledge transfer of a highly specific and complex technology/knowledge requires an active involvement of the teacher/supplier (Lane and Lubatkin, 1998). The findings confirm and support the previous empirical results of the effect of KCHAR on knowledge transfer; where knowledge-specific characteristics such as tacitness or ambiguous knowledge are more difficult to transfer for international ventures (Simonin, 1999a, 1999b; Pak and Park, 2004; Minbaeva, 2007). The results further suggest that KCHAR had significantly affected degree of explicit technologies because the technology supplier's specific technologies were well embodied within the component of their competencies, non-codifiable, highly personal, and deeply rooted in action, commitment, and involvement within a specific context (Reed and DeFillippi, 1990; Nonaka, 1994). The KCHAR involved the intangible factors embedded in the personal beliefs, experiences, and values in an organization; which caused the technology/knowledge is rather difficult to be formalized, communicated, transferred and shared between the alliance and IJV partners (Inkpen, 1998a; 2000). The results on the insignificant effect of KCHAR on TCTDEG are similar to Minbaeva's (2007) findings and therefore consistent with recent developments in knowledge transfer literature which suggested that KCHAR are not the only important determinant of knowledge transfer (Szulanski and Cappetta, 2003; Hansen and Lovas, 2004).

Building on the underlying integrated KBV and OL perspectives, this study has bridged the gaps in literature by empirically examining the effects of four critical inter-firm technology transfer characteristics: knowledge, technology recipient, technology supplier and relationship characteristic on two dimensions of degree of technology transfer: degree of tacit and explicit knowledge in a single holistic model. The holistic model advanced by this study and the use of Malaysian samples extend the empirical scope of TT and KT literature. From a review of literature, the holistic model of inter-firm TT advanced by this study has never been empirically tested before. Nonetheless, being probably the pioneer empirical study which examines the effects of all TTCHARS on TTDEG in a single model, one of the main study's limitations is that this study has mainly relied on the responses obtained from the top management level of the IJVs. Organizational members representing different levels and functions may also have unique contributions to make in assessing technology transfer characteristics and degree of technology transfer. Thus, the scope of respondents could have been broadened to include the middle and lower managerial levels in IJVs such as the technical, administrative and production managers who are directly involved in daily implementation of technology transfer between foreign and local partners. Secondly, as the major limitation of many organization studies in Malaysia, the response rate in terms of the number of usable questionnaires, though sufficient, was not encouraging. The low awareness of 
academic research among the respondents was the main obstacle to the study. Thirdly, consistent with the literature which suggests that IJVs in the developing countries are more unstable than IJVs in the developed countries, the nature of relationship between JV partners could have affected the results tremendously. The responses have a tendency to be biased should the respondents perceived that their IJVs were competitive in nature rather than collaborative. The subjectivity of the nature of relationship is difficult to capture. Fourthly, in this study the sample's population includes both established and relatively successful JVs. As the responses from the successful JVs were different from the surviving JVs, a replicating study could be conducted with samples that include these types of JVs. Finally, due to resource constraints the types of technology under investigation were confined to tacit and explicit knowledge. This study can be replicated to cover other dimensions of value chain activities such as marketing, production or management technology.

This empirical study is a response to the need for statistical evidence that has typically been lacking in inter-firm TT literature. Since this study focuses on degree of inter-firm TT, future studies could be conducted to further examine the effects of inter-firm technology transfer characteristics on level of innovation, competitiveness, productivity, and technological capabilities of local firms. The above relationship could also be extended to cover other formal inter-firm TT agents such as foreign direct investment (FDIs) and licensing. Secondly, it is worthwhile to extend the tacit and explicit dimensions of technology to cover other dimensions of supply chain activities. Future studies may focus on the relationships and effects of technology transfer characteristics on other dimensions of tacit and explicit technology/knowledge of supply chains such as production, marketing, management, and distribution. Thirdly, since the IJV literature has highlighted the high instability rate of IJVs in developing countries, future studies could be directed to empirically examine the relationships between degree of inter-firm technology transfer and conflicts, learning outcomes, asymmetric bargaining power, stability of JV, and equity ownership. Finally, given the linear relationship between technology transfer characteristics and degree of inter-firm technology transfer, future studies could further investigate the effects of few established moderating variables such as organizational culture, collaborative know-how, prior JV experience, and learning capacity on the relationship to provide new insights and information on the boundary conditions of the relationship.

\section{References}

Barney, J.B. (1991). Firm Resources and Sustained Competitive Advantage. Journal of Management, 17, p. 151-166. http://dx.doi.org/10.1177/014920639101700108

Bresman, H., Birkinshaw, J. \& Nobel, R. (1999). Knowledge Transfer in International Acquisitions. Journal of International Business Studies, 30(3), p. 439-62. http://dx.doi.org/10.1057/palgrave.jibs.8490078

Cavusgil, S.T., Calantone, R.J. \& Zhao, Y. (2003). Tacit Knowledge Transfer and Firm Innovation Capability. Journal of Business Industrial Marketing, 18(1), p. 6-21. http://dx.doi.org/10.1108/08858620310458615

Child, J. \& Faulkner, D. (1998). Strategies of Cooperation: Managing Alliances Networks and Joint Ventures. Oxford University, New York.

Chua, N. (2002). The Influence of Social Interaction on Knowledge Creation. Journal of Intellectual Capital, 3 (4), p. 375-392. http://dx.doi.org/10.1108/14691930210448297

Cohen, W. M. \& Levinthal, D.A. (1990). Absorptive Capacity: A New Perspective on Learning and Innovation. Administrative Science Quarterly, 35(1), p. 128-52. http://dx.doi.org/10.2307/2393553

Dhanaraj, C., Lyles, M.A., Steensma, H.K. \& Tihanyi, L. (2004). Managing Tacit and Explicit Knowledge Transfer in IJVs: the Role of Relational Embeddedness and the Impact on Performance. Journal of International Business Studies, 35(5), p. 428-42. http://dx.doi.org/10.1057/palgrave.jibs.8400098

Dierickx, I. \& Cool, K. (1989). Asset Stock Accumulation and Sustainability of Competitive Advantage. Management Science, 35, p. 1504-1541. http://dx.doi.org/10.1287/mnsc.35.12.1504

Doz, Y. L. \& Hamel, G. (1998). Alliance Advantage. Boston, MA: Harvard Business School Press.

Doz, Y. L. (1996). The Evolution of Cooperation in Strategic Alliances: Initial Conditions or Learning Processes? Strategic Management Journal, Summer Special Issue, 17, p. 55-83.

Fiol, C.M. \& Lyles, M.A. (1985). Organizational Learning. Academy of Management Journal, 10, p. 803-813.

Fryxell, Gerald, E., Robert, D.S. \& Maria, V. (2002). After the Ink Dries: The Interaction of Trust and Control in US-Based International Joint Ventures. Journal of Management Studies, 39, p. 865-887. http://dx.doi.org/10.1111/1467-6486.00315 
Geringer, J.M. (1991). Strategic Determinants of Partner Selection Criteria in International Joint Ventures. Journal of International Business Studies, 22(1), $1^{\text {st }}$ Quarter, p. 41-62. http://dx.doi.org/10.1057/palgrave.jibs.8490291

Gulati, R., (1995). Does Familiarity Breed Trust? The Implications of Repeated Ties for Contractual Choice in Alliances. Academy of Management Journal, 38(1), p. 85-112. http://dx.doi.org/10.2307/256729

Gupta, A. K. \& Govindarajan, V. (2000). Knowledge Flows within Multinational Corporations. Strategic Management Journal, $21(4), \quad$ p. $\quad$ 473-96. http://dx.doi.org/10.1002/(SICI)1097-0266(200004)21:4<473::AID-SMJ84>3.0.CO;2-I

Gupta, A. K. (1987). SBU Strategies, Corporate-SBU Relations, and SBU Effectiveness in Strategy Implementation. Academy of Management Journal, 30, p. 477-500. http://dx.doi.org/10.2307/256010

Hamel G. (1991). Competition for Determinant and Interpartner Learning within International Strategic Alliances. Strategic Management Journal, 12, p. 83-103. http://dx.doi.org/10.1002/smj.4250120908

Hansen, M. \& Lovas, B. (2004). How Do Multinational Companies Levarage Technoloical Competencies? Moving from Single to Interdependent Explanations. Strategic Management Journal, 25, 8/9, p.801-822. http://dx.doi.org/10.1002/smj.413

Hau, L. N. \& Evangelista, F. (2007). Acquiring Tacit and Explicit Markrting Knowledge from Foreign Partners in IJVs. Journal of Business Research, 60, pp. 1152-1165. http://dx.doi.org/10.1016/j.jbusres.2007.04.006

Huber, G. P. (1991). Organizational Learning: The Contributing Processes and the Literature. Organization Science, 2(1), p. 88-115. http://dx.doi.org/10.1287/orsc.2.1.88

Inkpen, A. C. (1998a). Learning and Knowledge Acquisition through International Strategic Alliances. The Academy of Management Executive, 12(4), p. 69-80. http://dx.doi.org/10.5465/AME.1998.1333953

Inkpen, A.C \& Dinur, A. (1998). Knowledge Management Processes and International Joint Ventures. Organization Science, 9(4), p. 454-468. http://dx.doi.org/10.1287/orsc.9.4.454

Inkpen, A.C. (1995a). The Management of International Joint Ventures: An Organizational Learning Perspective. London, UK: Routledge Press.

Inkpen, A.C. (2000). Learning through Joint Ventures: A Framework of Knowledge Acquisition. Journal of Management Studies, 37(7), p. 1019-1043. http://dx.doi.org/10.1111/1467-6486.00215

Kale P., Singh H. \& Perlmutter H. (2000). Learning and Protection of Proprietary Assets in Strategic Alliances: Building Relational Capital. Strategic Management Journal, 21(3), p. 217-37. http://dx.doi.org/10.1002/(SICI)1097-0266(200003)21:3<217::AID-SMJ95>3.0.CO;2-Y

Khanna, T., Gulati, R. \& Nohria, N. (1998). The Dynamics of Learning Alliances: Competition Cooperation, and Relative Scope. Strategic Management Journal, $19(3), \quad$ p. $\quad 193-210$. http://dx.doi.org/10.1002/(SICI)1097-0266(199803)19:3<193::AID-SMJ949>3.0.CO;2-C

Kim, L. (1998). Crisis Construction and Organizational Learning: Capability Building in Catching-up at Hyundai Motor. Organization Science, 9(4), p. 506-521. http://dx.doi.org/10.1287/orsc.9.4.506

Kogut, B. \& Zander, U. (1992). Knowledge of the Firm, Combinative Capabilities, and the Replication of Technology. Organization Science, 3(3), 383-97. http://dx.doi.org/10.1287/orsc.3.3.383

Kogut, B. \& Zander, U. (1993). Knowledge of the Firm and the Evolutionary Theory of the Multinational Corporation. Journal of International Business Studies, 24(4), p. 625-646. http://dx.doi.org/10.1057/palgrave.jibs.8490248

Lado, A. \& Wilson, M. (1994). Human Resource Systems and Sustained Competitive Advantage: A Competency-based Perspective. Academy of Management Review, 19, p. 699-727.

Lai, Y.W. \& Narayanan, S. (1997). The Quest for Technological Competence via MNCs: A Malaysian Case Study. Asian Economic Journal, 11(4), p. 407-422. http://dx.doi.org/10.1111/1467-8381.00045

Lane, P. J. \& Lubatkin, M (1998). Relative Absorptive Capacity and Interorganizational Learning. Strategic Management Journal, 461-77. http://dx.doi.org/10.1002/(SICI)1097-0266(199805)19:5<461::AID-SMJ953>3.0.CO;2-L

Lane, P. J., Salk, J.E. \& Lyles, M.A. (2001). Absorptive Capacity, Learning, and Performance in International Joint Ventures. Strategic Management Journal, 22(12), p. 1139-61. http://dx.doi.org/10.1002/smj.206 
Lin, X. (2005). Local Partner Acquisition of Managerial Knowledge in International Joint Ventures: Focusing on Foreign Management Control. Management International Review, 45(2), p. 219-237.

Lyles, M. A. \& Salk, J.E. (1996). Knowledge Acquisition from Foreign Parents in International Joint Ventures: An Empirical Examination in the Hungarian. Journal of International Business Studies, 29(2), p. 154-74.

Lyles, M. A., Sulaman M, Barden J. Q. \& Kechik ARBA (1999) Factors Affecting International Joint Venture Performance: A Study of Malaysian Joint Ventures. Journal of Asian Business, 15(2), p. 1-19.

Martin, X.Y.F. \& Salomon, R. (2003). Knowledge Transfer Capacity and its Implications for the Theory of the Multinational Corporation. Journal of International Business Studies, 34(4), 356-373. http://dx.doi.org/10.1057/palgrave.jibs.8400037

Minbaeva, D. (2007). Knowledge Transfer in Multinationals. Management International Review, 47(4), p. 567-593. http://dx.doi.org/10.1007/s11575-007-0030-4

Mohamed, M.Z (1998). Assessing the Competitiveness of the Malaysian Electronic and Electrical Industry: Part 1-Technology Adoption. Malaysian Management Review, 33(10), p. 19-20.

Nonaka, I. (1994). A Dynamic Theory of Organizational Knowledge Creation. Organization Science, 5, p. 14-37. http://dx.doi.org/10.1287/orsc.5.1.14

Pak, Y. \& Park, Y. (2004). A Framework of Knowledge Transfer in Cross-Border Joint Ventures: An Empirical Test of the Korean Context. Management International Review, 44(4), p. 435-455.

Polanyi, M. (1967). The Tacit Dimension. Anchor, Garden City, NY.

Porter, M.E. (1985). Competitive Advantage: Creating and Sustaining Superior Performance. Free Press: New York.

Pralahad, C.K. \& Hamel, G. (1990). The Core Competence of the Corporation. Harvard Business Review, 68, p. 77-91.

Reed, R. \& DeFillippi, R. J. (1990). Causal Ambiguity, Barriers to Imitation, and Sustainable Competitive Advantage. Academy of Management Review, 15, p. 88-102.

Rozhan, O., Rahayu \& Rashidah (2001). Great Expectation: CEO's Perception of the Performance Gap of the HRM functions in the Malaysian Manufacturing Sector. Personnel Review, 30 (1), 1\& 2, p. 61-80.

Sekaran, U. (2003). Research Methods for Business, Fourth Edition. John Wiley \& Sons, Inc.

Simonin, B. L. (1999a). Ambiguity and the Process of Knowledge Transfer in Strategic Alliances. Strategic Management Journal, $20(7), \quad$ p. $595-623$. http://dx.doi.org/10.1002/(SICI)1097-0266(199907)20:7<595::AID-SMJ47>3.0.CO;2-5

Simonin, B. L. (2004). An Empirical Investigation of the Process of Knowledge Transfer in International Strategic Alliances. Journal of International Business Studies, 35(5), 407-27. http://dx.doi.org/10.1057/palgrave.jibs.8400091

Simonin, B.L. (1999b). Transfer of Marketing Know-how in International Strategic Alliances: An Empirical Investigation of the Role and Antecedents of Knowledge Ambiguity. Journal of International Business Studies, 30(3) p. 463-90 [Third Quarter]. http://dx.doi.org/10.1057/palgrave.jibs.8490079

Smith, K.G., Carroll, S.J. \& Ashford, S.J. (1995). Intra and Inter Organizational: Towards a Research Agenda. Academy of Management Journal, 38(1), p.7-23. http://dx.doi.org/10.2307/256726

Steensma, H. K. \& Lyles, M.A. (2000). Explaining IJV Survival in a Transitional Economy through Social Exchange and Knowledge-based perspectives, Strategic Management Journal, 21(8), p. 831-51. http://dx.doi.org/10.1002/1097-0266(200008)21:8<831::AID-SMJ123>3.0.CO;2-H

Szulanski, G. \& Cappetta, R. (2003). Conceptualizing, Measuring and Predicting Difficulties in the Transfer of knowledge within Organizations, in Easterby-Smith, M \& Lyles, M. (eds.) The Blackwell Handbook of Organizational Learning and Knowledge Management. Oxford: Blackwell Publishing

Szulanski, G. (1996). Exploring Internal Stickiness: Impediments to the Transfer of Best Practice within the Firm. Strategic Management Journal, 17 (Winter Special Issue), p. 27-43.

Tihanyi, L. \& Roath, A.S. (2002). Technology Transfer and Institutional Development in Central and Eastern Europe. Journal of World Business, 37, p. 188-198. http://dx.doi.org/10.1016/S1090-9516(02)00077-9 
Uzzi, B. (1997). Social Structure and Competition in Interfirm Networks: The Paradox of embeddedness. Administrative Science Quarterly, 42, p. 35-67. http://dx.doi.org/10.2307/2393808

Wernerfelt, B. (1984). A Resource-Based View of the Firm, Strategic Management Journal, 5(2), p. 171- 80. http://dx.doi.org/10.1002/smj.4250050207

Williamson, O.E (1985). The Economic Institutions of Capitalism: Firms, Markets, Relational Contracting. Free Press, New York.

Winter, S. (1987). Knowledge and Competence as Strategic Assets, in: Teece, D. (Eds.), The Competitive Challenge. Massachusetts, Cambridge: Ballinger Publishing Company.

Yan, A. \& Luo, Y (2001). International Joint Ventures: Theory and Practice. M.E. Sharpe, New York.

Yin, E. \& Bao, Y. (2006). The Acquisition of Tacit Knowledge in China: An Empirical Analysis of the 'Supplier-side Individual Level' and 'Recipient-side' Factors. Management International Review, 46(3), p. 327-348. http://dx.doi.org/10.1007/s11575-006-0050-5

Zander, U. \& Kogut, B. (1995). Knowledge and the Speed of the Transfer and Imitation of Organizational Capabilities: An Empirical Test. Organization Science, 6(1), p. 76-92. http://dx.doi.org/10.1287/orsc.6.1.76

Table 1. Descriptive Statistics and Correlation Matrix

\begin{tabular}{|c|c|c|c|c|c|c|c|}
\hline Variable & Mean & SD & 1 & 2 & 3 & 4 & 5 \\
\hline KCHAR & 6.58 & 1.25 & 1.000 & & & & \\
\hline TRCHAR & 6.57 & 1.60 & $-0.182^{*}$ & 1.000 & & & \\
\hline TSCHAR & 4.14 & 1.64 & $0.296 * *$ & $0.304 * *$ & 1.000 & & \\
\hline RCHAR & 6.68 & 1.22 & $0.375^{* *}$ & $0.518 * *$ & $0.342 * *$ & 1.000 & \\
\hline TCTDEG & 5.91 & 1.45 & -0.145 & $0.428 * *$ & $0.328^{* *}$ & $0.502 * *$ & 1.000 \\
\hline KCHAR & 6.56 & 1.25 & 1.000 & & & & \\
\hline TRCHAR & 6.57 & 1.60 & $-0.182 * *$ & 1.000 & & & \\
\hline TSCHAR & 4.14 & 1.64 & $0.296 * *$ & $0.304 * *$ & 1.000 & & \\
\hline RCHAR & 6.68 & 1.22 & $0.375^{* *}$ & $0.518 * *$ & $0.342 * *$ & 1.000 & \\
\hline EXPDEG & 6.47 & 1.45 & -0.0 .106 & $0.442 * *$ & $0.398 * *$ & $0.581 * *$ & 1.000 \\
\hline
\end{tabular}

$n=128, * p<0.05, * * p<0.01$

Table 2. Results of group Regression Analysis ${ }^{\mathrm{a}}$

\begin{tabular}{lcc} 
Variable & $\begin{array}{c}\text { Degree of Tacit Knowledge } \\
\text { (Model 1) }\end{array}$ & $\begin{array}{c}\text { Degree of Explicit Knowledge } \\
\text { (Model 2) }\end{array}$ \\
\hline (Constant) & $4.962^{* * *}$ & $7.106^{* * *}$ \\
KCHAR & -0.079 & $-0.175^{*}$ \\
TRCHAR & $0.201^{* *}$ & $0.148 \dagger$ \\
TSCHAR & $0.164^{*}$ & $0.237^{* *}$ \\
RCHAR & $0.371^{* * *}$ & $0.489^{* * *}$ \\
$R$-squared & 0.314 & 0.424 \\
Adjusted $R$-squared & 0.292 & 0.407 \\
$F$ & $14.106^{* * *}$ & $22.753^{* * *}$
\end{tabular}

${ }^{a}$ Cell entries are standardised coefficient estimates $(n=128)$

$\dagger p<0.10, * p<0.05, * * p<0.01,{ }^{* * *} p<0.001$ 


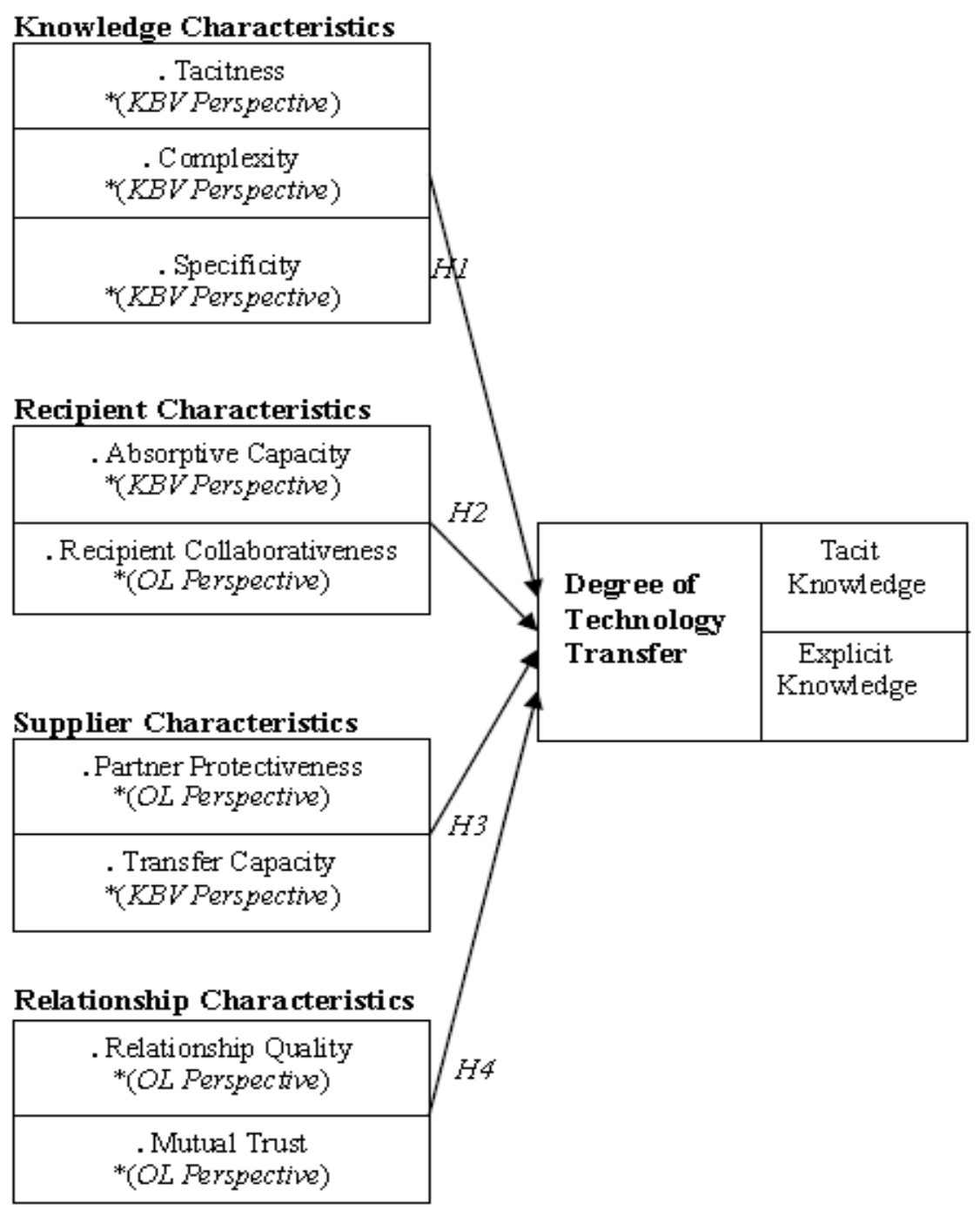

Figure 1. The Conceptual Model of Degree of Inter-firm Technology Transfer in IJVs 